\title{
SAFETY AND EFFICACY OF ORAL MIFEPRISTONE IN PRE-INDUCTION CERVICAL RIPENING IN INDUCTION OF LABOUR
}

\author{
Uma Mohanraj ${ }^{1}$, M. Mareeswari ${ }^{2}$
}

${ }_{1}^{1}$ Professor, Department of Obstetrics \& Gynaecology, KAPV Government Medical College, Trichy.

${ }_{2}^{2} 2^{\text {nd }}$ year Postgraduate Student, Department of Obstetrics \& Gynaecology, KAPV Government Medical College, Trichy.

\section{ABSTRACT}

\section{BACKGROUND}

Labour is a process through which the foetus moves from the intrauterine to the extrauterine environment. It is a clinical diagnosis defined as the initiation and perpetuation of uterine contractions with the goal of producing progressive cervical effacement and dilation. 'Prelabour' is a process in which both cervical ripening and myometrial excitement occurs finally culminating in the labour. Labour is a complex process in which involves interactions of many hormones like oestrogen, progesterone, prostaglandins, relaxin and second messengers and many other amines. Induction of labour is common in obstetric practice. According to the most current studies, the rate of induction of labour varies from 9.5 to 33.7 percent of all pregnancies ann ually. Successful induction of labour is closely related to the state of the cervix, which is assessed by the Bishop's score.

Objective- To compare the effect of oral mifepristone and the misoprostol in the pre-induction cervix ripening and induction of labour with only misoprostol in cervix ripening and labour induction in postdated pregnancy and to study the efficacy of the mifepristone over misoprostol.

\section{MATERIALS AND METHODS}

Antenatal mothers visiting the labour room in KAPV Govt. Medical College, Trichy with the sample size of 200 were selected. The mothers included in this study were those who completed 41 weeks of gestation and in 42nd (1-6 days) without any comorbidities. Those patients with medical illnesses like hypertension, diabetes, seizures, other obstetric complications like Anaemia, GDM, GHT, hypothyroid, seizure disorder were excluded from the study. 200 patients were randomly assigned two groups. First group (Group A) included patients who were given mifepristone followed by misoprostol as single dose after 48 hours. The second group (Group B) included patients who were given misoprostol 25 micrograms 3-4 doses every 4-6 hours. The two groups were studied. The results analysed were interval between the induction and delivery, improvement in Bishop's score, number of vaginal deliveries in each group, No. of caesarean deliveries in each group and also perinatal outcome which included the number of babies who were meconium stained in vaginal and caesarean delivery.

\section{RESULTS}

Mean induction to delivery interval was 3620 min. for Group A versus 2880 min. for Group B. The improvement in mean Bishop score was 35\% for Group A versus 32\% for Group B at the end of 24 hours. The outcome of induction of labour is assessed. In our study observation, the number of patients delivered vaginally within 24 hours were $13 \%$ in group A and $10 \%$ in group B, the number of patients delivered vaginally between 24 and 48 hours were $22 \%$ in group A and $50 \%$ in group B. The number of patients delivered between 48 and 72 hours were 55\% in group A and $12 \%$ in group B. The remaining 10 women (10\%) in group A and 28 women (28\%) underwent caesarean section. Analysing the perinatal outcome, in group A, meconium stained in vaginal delivery was 10 and meconium stained in caesarean delivery was only 2 . In group B, meconium stained in vaginal delivery was 22 , meconium stained in caesarean delivery was 20.

\section{CONCLUSION}

Mifepristone had modest effect on cervical ripening when given 48 hours before labour induction appearing to reduce the dose of misoprostol. The labour induction with mifepristone was associated with fewer caesarean deliveries. The occurrence of meconium-stained amniotic fluid is less in mifepristone group. No serious maternal morbidity occurred in both groups. The secondary outcome in relation to woman's satisfaction/caregiver's satisfaction is more in mifepristone group.

\section{KEYWORDS}

Mifepristone, Misoprostol, Induction of Labour.

HOW TO CITE THIS ARTICLE: Mohanraj U, Mareeswari M. Safety and efficacy of oral mifepristone in pre-induction cervical ripening in induction of labour. J. Evolution Med. Dent. Sci. 2017;6(12):922-926, DOI: 10.14260/Jemds/2017/197

Financial or Other, Competing Interest: None.

Submission 05-12-2016, Peer Review 25-01-2017,

Acceptance 31-01-2017, Published 09-02-2017.

Corresponding Author:

Dr. Uma Mohanraj,

13, Seshapuram, Thennur,

Trichy-17,

Tamilnadu.

E-mail: armohanraj87@gmail.com

DOI: $10.14260 /$ jemds $/ 2017 / 197$

(c) $(\mathrm{i})(\mathrm{B}$

\section{BACKGROUND}

Labour is a process through which the foetus moves from the intrauterine to the extrauterine environment. It is a clinical diagnosis defined as the initiation and perpetuation of uterine contractions with the goal of producing progressive cervical effacement and dilation. Induction of labour is the intervention intended to artificially initiate uterine contractions resulting in the cervical changes (RCOG 2001). ${ }^{1}$ Nowadays, induction of labour is on the rising trends due to improved use of the ultrasound, for gestational age, due to the risk of severe maternal outcomes and due to litigation 
constraints. The ideal inducing agent should achieve the onset of labour within the shortest possible time and should not increase the rate of caesarean sections or operative vaginal deliveries.

Induction of labour is common in obstetric practice. According to the most current studies, the rate of induction of labour varies from 9.5 to 33.7 percent of all pregnancies annually. Successful induction of labour is closely related to the state of the cervix, which is assessed by the Bishop's score.

Mifepristone (Mifeprex) is an antiprogesterone agent. Progesterone inhibits contractions of the uterus, while mifepristone counteracts this action. The rationale behind its use is that fall in the level of progesterone is one of the main factors leading to the onset of labour, many studies have showed that it is effective in cervical ripening. When compared to the placebo, it is more effective in increasing the chances of spontaneous labour (Lelaidier et al 1993). ${ }^{2}$

Calkins and colleagues were the first to carry out systematic studies of the factors influencing the duration of the first stage of labour. ${ }^{3}$ They concluded that the length, thickness, and particularly the consistency of the cervix were important parameters. Bishop originally described a scoring system in 1964. It showed that the time taken for the women to enter into labour is inversely proportional to the cervical score. The modern scoring system is Calder scoring system. The cervix is said to be unfavourable if the score is below 6 . It can be used for unfavourable cervix as a pre-induction ripening agent.

Misoprostol is an inexpensive analogue of prostaglandin E1. It is more stable and can be stored easily in room temperature. It is rapidly absorbed both vaginally and orally. The American College of Obstetrics and Gynecology (ACOG 2009) recommends the use of 25 microgram per vaginum. 4 The frequency should not be more than every 3-6 hours. Risks also include tachysystole, defined as five or more uterine contractions in 10 minutes for two consecutive 10minute periods and meconium-stained liquor.
Antenatal mothers visiting the labour room in KAPV Govt. Medical College, Trichy with the sample size of 200 were selected. The duration of the study was 6 months (July 2016 Nov 2016). The mothers included in this study were those who had completed 41 weeks of gestation and in $42^{\text {nd }}$ (1-6 days) and only singleton cephalic foetus without any comorbidities for both mother and foetus. Those patients with medical illness like hypertension, diabetes, seizures, other obstetrics complication like Anaemia, GDM, GHT, hypothyroid, seizure disorder were excluded from the study. 200 patients were randomly assigned two groups. First group (Group A) included patients who were given mifepristone followed by misoprostol as single dose after 48 hours. The second group (Group B) included patients who were given misoprostol 25 micrograms 3-4 doses every 4-6 hours. The two groups were studied. The results analysed were interval between the induction and delivery, improvement in Bishop's score, number of vaginal deliveries in each group, no. of caesarean deliveries in each groups and also perinatal outcome which included the number of babies who were meconium stained in vaginal and caesarean delivery.

The primary outcomes chosen as being most representative of the clinically important measures of effectiveness and complication.

- Number of Vaginal delivery.

- Mean induction delivery interval time.

- Number of caesarean section.

- Neonatal morbidity.

- Maternal morbidity if any.

The secondary outcome like

- Woman's satisfaction.

- Caregiver's satisfaction was also analysed.

\section{RESULTS}

Table 1 shows both the groups were comparable regarding maternal age, parity and gestational age.

\section{MATERIALS AND METHODS}

\begin{tabular}{|c|c|c|c|c|}
\hline Variables & A & B & F- Calculated Value & F-Table Value at 5\% Level \\
\hline Age & $22.2 \pm 2$ & $23.5 \pm 0.81$ & $0.945^{*}$ & \multirow{2}{*}{1.35} \\
\hline Parity & $1.8 \pm 0.752$ & $1.7 \pm 0.644$ & $1.059^{*}$ & \\
\hline Gestational Age & $40.13 \pm 0.338$ & $40.15 \pm 0.359$ & $1.00^{*}$ & \\
\hline \multicolumn{2}{r}{ Table 1. Characteristics of the Study Subjects } \\
\hline
\end{tabular}

Values are mean of 100 observations \pm Standard

*Values are not significant at $5 \%$ level.

Deviation

The calculated value of $\mathrm{F}$ is less than the table value of $\mathrm{F}$. Therefore, the hypothesis is true. Thus, we may conclude that it does not get influenced by age, parity and gestational age of the sample groups.

Table 2 \& 3 show mean induction to delivery interval was 3620 min. for Group A versus 2880 min. for Group. A. The improvement in mean Bishop score was 35 for Group B versus 32 for Group. 


\begin{tabular}{|c|c|c|c|}
\hline Sl. No. & Variable & $M-M(n=100)$ & M180 (n=100) \\
\hline & Mean Bishop's Score at the end of 24 hours & $35(35 \%)$ & $32(32 \%)$ \\
\hline & $\begin{array}{l}\text { Mode of delivery } \\
\text { Vaginal delivery } \\
\text { within } 24 \text { hours }\end{array}$ & $13(13 \%)$ & $10(10 \%)$ \\
\hline & $\begin{array}{c}\text { Vaginal delivery } \\
\text { between } 24 \text { and } 48 \text { hours }\end{array}$ & $22(22 \%)$ & $50(50 \%)$ \\
\hline & $\begin{array}{c}\text { Vaginal delivery } \\
\text { between } 48 \text { and } 72 \text { hours }\end{array}$ & $55(55 \%)$ & $12(12 \%)$ \\
\hline & LSCS & $10(10 \%)$ & $28(28 \%)$ \\
\hline & Mean induction delivery interval (min.) & 3620 min. & 2880 min. \\
\hline & \multicolumn{3}{|c|}{ Outcome } \\
\hline & $\begin{array}{l}\text { Meconium-stained } \\
\text { Vaginal delivery }\end{array}$ & $10(10 \%)$ & $22(22 \%)$ \\
\hline & $\begin{array}{l}\text { Meconium-stained } \\
\text { Caesarean delivery }\end{array}$ & $2(2 \%)$ & $20(20 \%)$ \\
\hline
\end{tabular}

\begin{tabular}{|c|c|c|c|}
\hline Day-I & $13(12.78)[0.00]$ & $10(10.22)[0.00]$ & 23 \\
\hline 24-48 hours & $22(40.00)[8.10]$ & $50(32.00)[10.12]$ & 72 \\
\hline $60-72$ hours & $55(37.22)[8.49]$ & $12(29.78)[10.61]$ & 67 \\
\hline & $\begin{array}{c}\text { The chi-square statistic is 37.3382. } \\
\text { The p-value is < 0.00001. } \\
\text { The result is significant at } \\
\text { Columns total }\end{array}$ & 72 & 162 \\
& $\begin{array}{c}\text { (Grand total) } \\
\end{array}$ & & \\
\hline
\end{tabular}

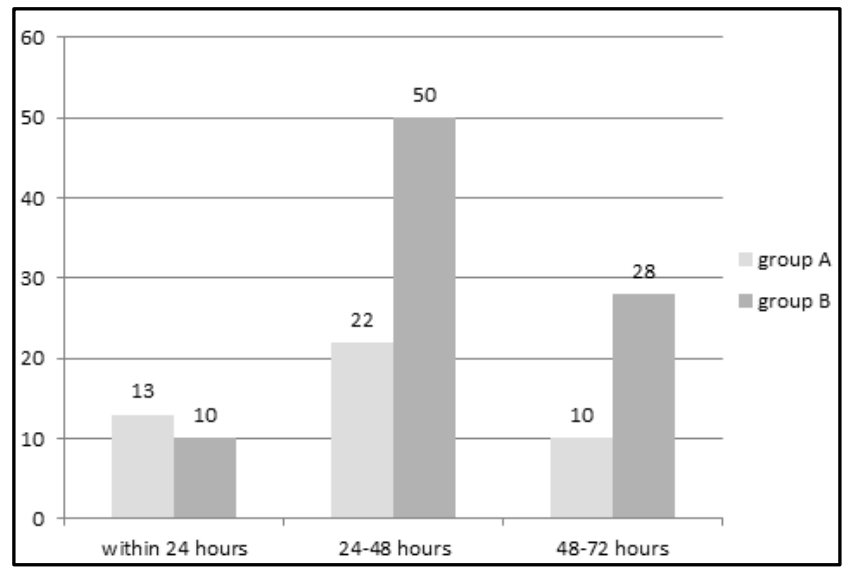

Figure 1. Comparison of Vaginal Delivery between Two Groups

Mean induction to delivery interval was $3620 \mathrm{~min}$. for Group A versus 2880 min for Group B The improvement in mean Bishop score was 35\% for Group A versus 32\% for Group B at the end of 24 hours. The outcome of induction of labour is assessed. In our study observation, the number of patients delivered vaginally within 24 hours were $13 \%$ in group A and $10 \%$ in group B, the number of patients delivered vaginally between 24 and 48 hours were $22 \%$ in group A and $50 \%$ in group B. The number of patients delivered between 48 and 72 hours were $55 \%$ in group A and $12 \%$ in group B. The remaining 10 women (10\%) in group A and 28 women (28\%) underwent caesarean section.

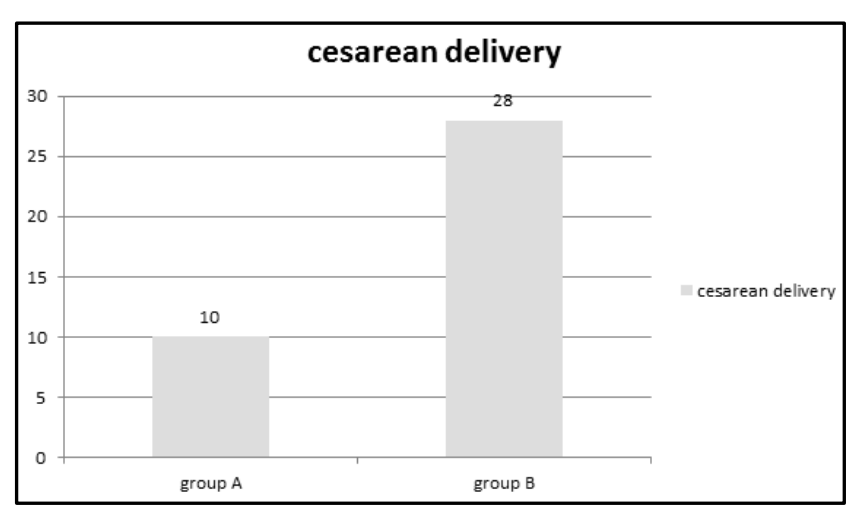

Figure 2. Comparison of Caesarean Delivery between 2 Groups

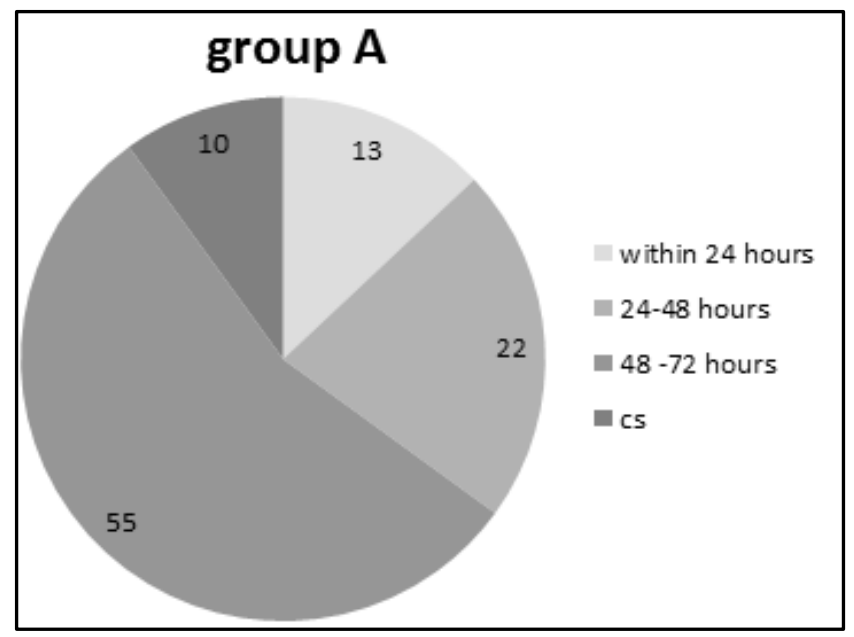

Figure 3. Comparison of Modes of Deliveries- Vaginal (induction - delivery time) and Caesarean in Group A 


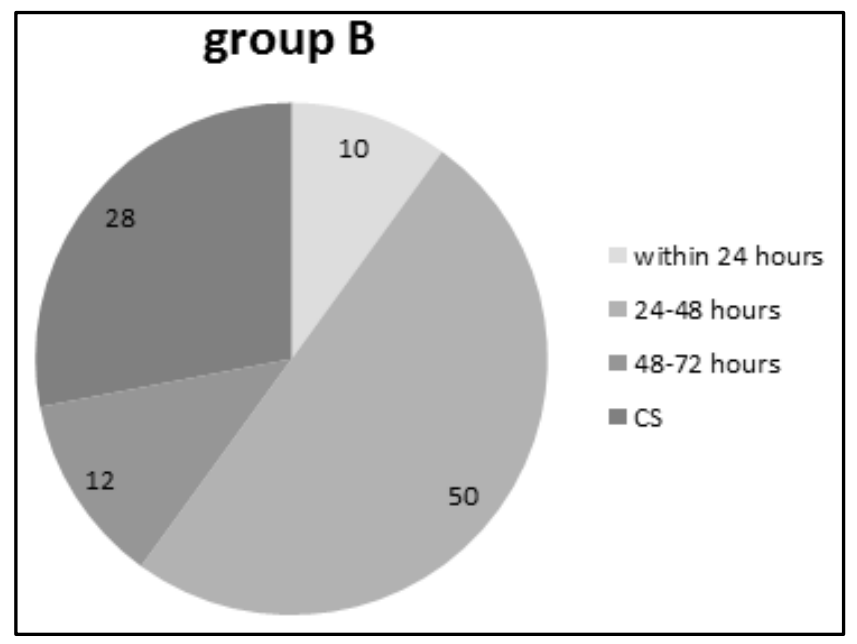

Figure 4. Comparison of Modes of Deliveries- Vaginal (induction - delivery time) and Caesarean in Group B

Table 4 shows 90 women (90\%) in group A delivered vaginally and 10 women $(10 \%)$ delivered by caesarean in group A. In group B $72(72 \%)$ delivered vaginally and $28(28 \%)$ delivered by caesarean. 5 This is found to be statistically significant.

\begin{tabular}{|c|c|c|c|}
\hline & Group A & Group B & $\begin{array}{c}\text { Marginal } \\
\text { Row } \\
\text { Totals }\end{array}$ \\
\hline Caesarean & $10(19)[4.26]$ & $28(19)[4.26]$ & 38 \\
\hline Vaginal & $90(81)[1]$ & $72(81)[1]$ & 162 \\
\hline $\begin{array}{c}\text { Marginal } \\
\text { Column } \\
\text { Totals }\end{array}$ & $\mathbf{1 0 0}$ & $\mathbf{1 0 0}$ & $\begin{array}{c}\mathbf{2 0 0} \\
\text { (Grand } \\
\text { Total) }\end{array}$ \\
\hline \multicolumn{2}{|c|}{ Table 4. Caesarean vs. Vaginal Deliveries }
\end{tabular}

The chi-square statistic is 10.5263 .

The p-value is .001177 .

This result is significant at $\mathrm{p}<.05$.

The perinatal outcome in group A in my study is shown in Table 5. The meconium-stained liquor in vaginal delivery is found to be only 10 babies. The meconium stained in caesarean delivery is only 2 babies in Group A. In group B, 22 babies were found to be meconium stained in vaginal delivery, 20 babies were found to be meconium stained in caesarean delivery. This is found to be statistically significant.

\begin{tabular}{|c|c|c|c|}
\hline & Group A & Group B & $\begin{array}{c}\text { Row } \\
\text { Totals }\end{array}$ \\
\hline $\begin{array}{c}\text { Meconium- } \\
\text { stained vaginal }\end{array}$ & $\begin{array}{c}10(14.11) \\
{[1.20]}\end{array}$ & $\begin{array}{c}22(17.89) \\
{[0.94]}\end{array}$ & 32 \\
\hline Caesarean & $2(9.70)[6.11]$ & $\begin{array}{c}20(12.30) \\
{[4.82]}\end{array}$ & 22 \\
\hline \multicolumn{3}{|c|}{ Table 5. Neonatal Outcome } \\
\hline
\end{tabular}

The chi-square statistic is 16.3329 .

The p-value is .000969 .

The result is significant at $\mathrm{p}<.05$.

Table 6 shows the adverse perinatal outcome was assessed between healthy baby and babies with meconiumstained liquor. In group A, perinatal death is 1 and NICU admission is 6. In group B, perinatal death is 2 and NICU admission is 6 . The result is not significant.

\begin{tabular}{|c|c|c|c|}
\hline Sl. No. & Variable & Group A & Group B \\
\hline 1. & Perinatal death & $1(1.11)[0.01]$ & $2(1.89)[0.01]$ \\
\hline 2. & NICU admission & $6(5.89)[0]$ & $10(10.11)[0]$ \\
\hline \multicolumn{4}{|c|}{ Table 6. Perinatal Outcome } \\
\hline
\end{tabular}

The $\mathrm{p}$ - value is 0.8908 .

This result is not significant at $\mathrm{p}<0.05$.

\section{DISCUSSION}

Mifepristone is a synthetic steroid with a antiprogestational action as a result of competition with progesterone at the progesterone receptors at doses ranging from 3 to $10 \mathrm{mg} / \mathrm{kg}$ orally, it inhibits the action of endogenous or exogenous progesterone in different animal species. This action is manifested in the form of pregnancy termination in rodents.

In women at a dose greater than or equal to $1 \mathrm{mg} / \mathrm{kg}$, mifepristone antagonises the endometrial and myometrial effects of progesterone during pregnancy it sensitises the myometrium to the contraction inducing action of prostaglandins. The maximal effect is achieved when prostaglandins was administered 36-48 hours after mifepristone.

Mifepristone induces softening and dilation of cervix, softening and dilatation has been shown to be detectable from 24 hours after administration of mifepristone and increases to a maximum at approximately 36-48 hours after administration.

Mifepristone binds to the glucocorticoid receptor. In animals at doses of $10-25 \mathrm{mg} / \mathrm{kg}$, it inhibits the action of dexamethasone. In men, the anti-glucocorticoid action is manifested at a dose equal to or greater than $4.5 \mathrm{mg} / \mathrm{kg}$ by a compensatory elevation of ACTH and cortisol. Glucocorticoid bioactivity (GBA) may be depressed for several days following a single administration of $200 \mathrm{mg}$ mifepristone for termination of pregnancy. The clinical implications of this are unclear, however vomiting and nausea may be increased in susceptible women. Mifepristone has a weak anti-androgenic action which only appears in animals during prolonged administration of very high doses.

The dynamic changes in collagen structure rather than collagen content may regulate remodelling. Hyaluronidase and glycosaminoglycans, a carbohydrate polymer is found in cervix and its breakdown is caused by large to small molecules. Increased activity of the hyaluronidase enzyme is seen in term pregnant woman for ripening.

During cervix ripening, there are changes in the stromal invasion with inflammatory cells that secrete proteases that aid in the degradation of collagen. The labour onset is the culmination of series of changes in the uterus and cervix during the first $36-38$ weeks of gestation, the myometrium is in the preparatory phases yet unresponsive state, concurrently, the cervix begins at early stage of remodelling termed softening - yet maintains structural integrity in transitional phase, the cervix undergoes ripening, effacement and loss of structural integrity.

The cascade of events that allows cervical ripening are induced by decreasing serum progesterone concentration. Administration of progesterone antagonists causes cervical ripening. The role of sex steroid hormone is that 
progesterone inhibits and oestrogen promotes the event leading to parturition.

So, progesterone withdrawal, precedes progression of phase 1 to phase 2 of parturition. Administration of progesterone - receptor antagonists, mifepristone (RU-486) will promote some or all key features of parturition. These include cervix ripening, increased uterine sensitivity to uterotonics. Progesterone can promote expression of inhibitory transcription that can inhibit expression of CAPs.

In our study group, statistically, a significant improvement was observed in mean Bishop's score at the end of 24 hours. Indirectly, this improvement in Bishop's score indicates the progesterone withdrawal support as compared to Wing study group who demonstrated more women had favourable Bishop's score at the end of 24 hours of mifepristone alone than misoprostol only.

A decrease in the misoprostol requirement with prior use of mifepristone in our study was found to be statistically significant. Our results were similar with the past studies that shows decreased prostaglandin requirements when mifepristone is used at post term induction. Wing et al also reported the reduced need of prostaglandin/oxytocin need in mifepristone group. ${ }^{6}$

We found in our study, there were no major complications, more spontaneous vaginal delivery, less incidence of LSCS deliveries consistent with study conducted by Athawale et al. ${ }^{7}$ More spontaneous vaginal deliveries and less incidence of LSCS deliveries were noted by Fatima et al. ${ }^{8}$ Hapangama and Neison reported that mifepristone-treated women were less likely to undergo caesarean section. ${ }^{9}$ Woman's satisfaction is more in our study group as mode of induction is more akin to natural labour.

\section{CONCLUSION}

Mifepristone had a modest effect on cervical ripening when given 48 hours before labour induction appearing to reduce the dose of misoprostol. The labour induction with mifepristone was associated with fewer caesarean deliveries. ${ }^{10}$ The occurrence of meconium-stained amniotic fluid is less in mifepristone. No serious maternal morbidity occurred in both groups. The secondary outcome in relation to woman's satisfaction is more in mifepristone group.

The mifepristone is found to produce less rapid onset of labour, a process more akin to natural labour in my studies.

\section{REFERENCES}

[1] Royal College of Obstetricians and Gynaecologists: setting standards to improve women's health. Induction of labour, evidence-based clinical guideline number 9 . 2001:49-52. ISBN 1-900364-50-6.

[2] Lelaidier C, Frydman R, Baton-Saint-Mleux C, et al. labour induction in women at term with mifepristone (RU 486): a double blind randomized, placebocontrolled study. Obset Gynecol 1992;80(6):972-5.

[3] Cartwright A. Mother's experience of induction. BM] 1977;2(6089):745-49.

[4] ACOG Committee on Practice Bulletins -- Obstetrics. ACOG practice bulletin no. 107: induction of labor. Obstet Gynecol 2009;114(2 Pt 1):386-97.

[5] Conway DL, Adkins WB, Schroeder B, et al. Isolated oligohydramnios in the term pregnancy: is it a clinical entity? J Matern Fetal Med 1998;7(4):197-200.

[6] Wing DA, Mishell DR, Fassett MJ. Mifepristone for preinduction cervical ripening beyond 41 weeks gestation: a randomized controlled trial. Obstet Gynecol 2000;96(4):543-8.

[7] Athawale R, Acharya N, Samal S, et al. Effect of mifepristone in cervical ripening for induction of labour. Int J Reprod Contracept Obset Gynecol 2013;2(1):35-8.

[8] Fathima S, Nayak SR, Rao B, et al. Mifepristone in induction of labour at term. Int J of pham Biomed Res 2013;4(3):164-6.

[9] Heikinheimo 0, Kekkonen R, Lahteenmaki P. The pharmacokinetics of mifepristone in humans reveal insights into differential mechanisms of antiprogestin action. Contraception 2003;68(6):421-6.

[10] Neilson JP. Mifepristone for induction of labour. Cochrane Database Sys Rev 2000;(4):CD002865. 